\title{
Dinâmica do desenvolvimento das gônadas de Parastacus varicosus (Crustacea, Decapoda, Parastacidae)
}

\author{
Daiana da Silva Castiglioni ${ }^{1}$, Guendalina Turcato de Oliveira $^{2}$ \& Georgina Bond-Buckup ${ }^{1}$
}

1. Laboratório de Carcinologia, Departamento de Zoologia, PPG Biologia Animal, Universidade Federal do Rio Grande do Sul, Av. Bento Gonçalves, 9500, prédio 43435, 91501-970 Porto Alegre, RS, Brasil. (daicastiglioni@yahoo.com.br)

2. Faculdade de Biociências, Departamento de Ciências Biológicas, Pontifícia Universidade Católica do Rio Grande do Sul, Av. Ipiranga, 6681, prédio 12, 90619-900 Porto Alegre, RS, Brasil.

\begin{abstract}
Dynamics of gonadal development of Parastacus varicosus (Crustacea, Decapoda, Parastacidae). The level of gonadal development of a species can be evaluated by the determination of the gonadossomatic (GSI) and the hepatossomatic (HSP) indices. The hepatopancreas is the most important centre for storage of reserves in decapods, which can be transferred to the gonads during their development. The aim of this study was to estimate gonadal development of Parastacus varicosus Faxon, 1898 by means of macro and microscopic observations, as well by the inspection of the variations of gonadossomatic and hepatossomatic indices. The crayfishes were collected in the Gravataí hydrographic basin, Cova do Touro locality, State of Rio Grande do Sul, Brazil. Female's gonads were weighted for the recognition of the gonadossomatic index and histological analysis. Hepatopancreas weight was also obtained to determine the hepatossomatic index. The results showed a decrease of the hepatossomatic index and an increase of the gonadossomatic index in females during the seasonal transition period from spring to summer, suggesting a possible transfer of the hepatopancreatic reserves to the gonads during the reproductive period. However, considering that this decrease did not show significance at $p>0.05$ level, it is likely that other tissues contribute for this transfer, as hemolymph, for instance.
\end{abstract}

KEYWORDS. Crayfish, gonadossomatic index, maturation.

RESUMO. O desenvolvimento das gônadas de uma espécie pode ser avaliado pela determinação do índice gonadossomático e hepatossomático. O hepatopâncreas é o maior centro de reservas em decápodos e essas reservas podem ser transferidas para as gônadas durante o seu desenvolvimento. O objetivo desta pesquisa foi avaliar, no lagostim Parastacus varicosus Faxon, 1898, o desenvolvimento das gônadas, por meio de observações macro e microscópicas, além de determinar a variação dos índices gonadossomático e hepatossomático. Os lagostins foram amostrados na bacia hidrográfica do rio Gravataí, localidade Cova do Touro, Estado do Rio Grande do Sul. As gônadas das fêmeas foram pesadas para a determinação do índice gonadossomático e para análise histológica. O peso do hepatopâncreas também foi obtido para a determinação do índice hepatossomático. Os resultados mostraram uma diminuição do índice hepatossomático e um aumento do índice gonadossomático das fêmeas, no período de passagem da primavera para o verão, o que sugere uma possível transferência das reservas do hepatopâncreas para a gônada no período reprodutivo. No entanto, considerando que essa diminuição não foi significativa ao nível de 0,05 , sugere-se que outros tecidos e/ou a hemolinfa possam estar contribuindo com a transferência de suas reservas.

PALAVRAS-CHAVE. Índice gonadossomático, lagostim, maturação.

O desenvolvimento das gônadas, em crustáceos decápodos, pode ser acompanhado pelas modificações que ocorrem nos ovários durante o ciclo reprodutivo, em que há multiplicação de células gonadais e crescimento dos gametas para a maturação, ovulação e oviposição (GrASSÉ, 1996). Durante essas fases, a gônada feminina sofre modificações como alteração da cor e tamanho, enquanto na gônada masculina, as modificações morfológicas não são tão evidentes (CAVALLI et al., 2001; KROL et al., 1992).

O desenvolvimento das gônadas pode determinar o período e o tamanho em que o animal atinge a maturidade sexual, sendo caracterizado como o conjunto de transformações morfológicas e fisiológicas mediante as quais os juvenis ou imaturos alcançam a capacidade de produzir gametas, que podem fecundar ou ser fecundados (Mantelatto \& Fansozo, 1997). Para os crustáceos, nem sempre existem características externas como cor e tamanho que, de maneira direta e inequívoca, informam sobre o momento exato em que os indivíduos alcançam a maturidade sexual.

A maturidade sexual fisiológica pode ser reconhecida pela análise histológica das gônadas e ductos genitais, onde pode ser revelado um desenvolvimento heterogêneo das células, passando por vários estágios de diferenciação durante o desenvolvimento (Mantelatto \& Fransozo, 1997). A maturidade sexual foi investigada em várias espécies de decápodos que ocorrem no Brasil, destacando-se os artigos publicados por ReIGADA \& Negreiros-Fransozo (1999), CAstiglioni \& SAntos (2001), Baptista-Metri et al. (2005) е Сово \& Fransozo (2005).

$\mathrm{O}$ índice gonadossomático vem sendo utilizado como um método qualitativo na determinação do período reprodutivo de uma espécie avaliando os estágios de desenvolvimento. Esse índice expressa a porcentagem que as gônadas representam no peso total do corpo dos indivíduos (Grant \& Tyler, 1983; Haefner \& SpaArgaren, 1993; Vazzoler, 1996; López-Greco \& RODRíGUEZ, 1999).

A sazonalidade do desenvolvimento das gônadas está associada com o armazenamento de reservas orgânicas e minerais nos tecidos somáticos, que são transferidas para as gônadas durante a gametogênese (LAWRENCE, 1976). Portanto, como o hepatopâncreas dos 
crustáceos é o maior centro de reservas orgânicas e inorgânicas em decápodos (GIBSON \& BARKER, 1979), é esperado que ocorra uma mobilização dessas reservas energéticas para a maturação das gônadas, mostrando assim valores dos índices gonadossomáticos e hepatossomáticos antagônicos, como vem sendo observado em crustáceos decápodos (PILlay \& NAIR, 1973; Kyomo, 1988; Haefner \& SpaArgaren, 1993; Chu, 1995; LÓPEZ-GRECO \& RODRÍGUEZ, 1999).

O índice gonadossomático foi avaliado em algumas espécies de decápodos, como no caranguejo Chasmagnathus granulatus Dana, 1851 por LóPEZ-GRECO \& Rodríguez (1999), nos camarões carídeos Crangon crangon (Linnaeus, 1758) e Exopalaemon modestus (Heller, 1862) por HAEFNER \& SpAARGAREN (1993) е Он et al. (2002), respectivamente, e no camarão penaeídeo Metapenaeus joyneri (Miers, 1880) pesquisado por $\mathrm{CHU}$ (1995). Nos lagostins Procambarus clarkii (Girard, 1852), Cherax quadricarinatus (Von Martens, 1868) e $C$. quinquecarinatus Gray, 1845 o desenvolvimento das gônadas também foi acompanhado pela aplicação desse índice (KulKaRni et al., 1991; SAGi et al., 1996 e BEATTY et al., 2005, respectivamente).

No entanto, até o momento, nenhuma pesquisa foi realizada sobre o desenvolvimento das gônadas dos lagostins do gênero Parastacus Huxley, 1879 com a avaliação do índice gonadossomático. Visando contribuir com informações referentes à biologia reprodutiva desses crustáceos, objetiva-se avaliar o desenvolvimento das gônadas em Parastacus varicosus Faxon, 1898.

\section{MATERIAL E MÉTODOS}

As amostragens de $P$. varicosus foram realizadas mensalmente no período de junho de 2004 a maio de 2005. Os locais de coleta foram um arroio e tanques de criação de peixes, em uma propriedade particular na localidade Cova do Touro, pertencente à bacia hidrográfica do rio Gravataí, Rio Grande do Sul (2952'33,9”S; 51 '0'51,7’W). Os lagostins foram capturados com armadilhas iscadas com fígado de boi - retirados após dois dias -, puçás e uma bomba de sucção.

Os exemplares foram medidos quanto ao comprimento do cefalotórax $(\mathrm{mm})$ com um paquímetro digital $(0,01 \mathrm{~mm})$ e pesados em uma balança eletrônica (precisão de 0,001 g). As gônadas foram observadas quanto à coloração. Para as fêmeas registrou-se o peso do ovário e o peso do hepatopâncreas, enquanto para os machos foi verificado apenas o peso do hepatopâncreas.

Os estágios de desenvolvimento dos ovários foram caracterizados de acordo com a coloração e tamanho: o estágio I foi representado pelo ovário imaturo de coloração branca, o estágio II pelo ovário em desenvolvimento e amarelado e o estágio III pelo ovário desenvolvido e com coloração verde-oliva.

Para estimar o tamanho em que os lagostins atingem a maturidade sexual, as gônadas foram analisadas microscopicamente, seguindo-se as etapas de rotina em preparação histológica. O material foi observado quanto à presença de oócitos em vitelogênese secundária nas fêmeas, enquanto nos machos foi analisada a presença de espermátides e/ou espermatozóides.
O índice gonadossomático (IG) e hepatossomático (IH) foram determinados segundo GRANT \& TYLER (1983) e VAZZOLER (1996) pelas seguintes equações: $\mathrm{IG}=(\mathrm{PG} /$ $\mathrm{PA}) \mathrm{X} 100$ e IH = (PH/PA) X 100, em que PG, PA e PH é, respectivamente, os pesos da gônada, do lagostim e do hepatopâncreas.

Os resultados foram analisados utilizando-se o teste de análise de variância (ANOVA - one way), complementado com o teste de Tukey (ZAR, 1996). Na comparação entre os índices gonadossomático e hepatossomático utilizou-se o teste de análise de variância (ANOVA - two way) (ZAR, 1996). O nível de significância adotado foi de $5 \%$ e as análises estatísticas realizadas no programa SPSS (Statistical Package for the Social Sciences).

\section{RESULTADOS}

O desenvolvimento das gônadas de $P$. varicosus foi avaliado em machos $(n=40)$, cujo comprimento de cefalotórax (CC) variou de 8,25 a $39,85 \mathrm{~mm}(26,81 \pm 0,736)$ e o peso de $6,70 \mathrm{~g} \pm 0,57$ (média \pm erro padrão); em fêmeas $(\mathrm{n}=50)$, o tamanho variou de 12,55 a $37,06 \mathrm{~mm}$ de CC $(28,26 \pm 0,842) \mathrm{e}$ o peso médio de 7,24g $\pm 0,53$ (média \pm erro padrão).

A amplitude do tamanho do CC foi maior nas fêmeas com gônadas imaturas, sendo que as fêmeas com gônadas em desenvolvimento e as desenvolvidas apresentaram praticamente a mesma variação (Tab. I). A presença de gônadas imaturas em fêmeas a partir de 12,55 até 35,08 $\mathrm{mm}$ de $\mathrm{CC}$ sugere a ocorrência de sucessivas desovas.

Foi observado um aumento significativo no tamanho dos ovários (peso) no estágio III (Fig. 1), enquanto que o peso das gônadas não mostrou diferença entre o estágio I e II ( $\mathrm{p}>0,05)$. Nas fêmeas examinadas (n $=50$ ), foi observada a predominância dos ovários no estágio III, correspondendo a $48 \%$, seguido pelo estágio I com $36 \%$, e o estágio II com a menor freqüência, $16 \%$. Foi observada a predominância do estágio III no período do inverno até o verão (Fig. 2).

O menor valor do índice gonadossomático (IG) foi observado no outono $(0,31)$ e o maior valor no verão $(3,16)$. O valor mais baixo do índice hepatossomático (IH) foi verificado, também, no outono $(6,16)$ e o valor mais elevado na primavera (7,29) (Fig. 3).

Com relação aos estágios dos ovários (Fig. 4), observou-se um aumento do IG no estágio mais desenvolvido - estágio III ( $\mathrm{p}<0,05)$-, enquanto que entre os estágios I e II não foi verificada diferença significativa. $\mathrm{O}$ IH não mostrou variação à medida que os ovários se desenvolvem $(\mathrm{p}>0,05)$.

Tabela I. Caracterização biométrica dos indivíduos de Parastacus varicosus Faxon, 1898 nos diferentes estágios do desenvolvimento dos ovários ( $\mathrm{CC}$, comprimento do cefalotórax, em $\mathrm{mm}$ ).

\begin{tabular}{lccc}
\hline & $\begin{array}{c}\text { Estágio I } \\
(\mathrm{n}=18)\end{array}$ & $\begin{array}{c}\text { Estágio II } \\
(\mathrm{n}=8)\end{array}$ & $\begin{array}{c}\text { Estágio III } \\
(\mathrm{n}=24)\end{array}$ \\
\hline $\begin{array}{l}\text { Peso médio }(\mathrm{g}) \\
\pm \text { erro padrão }\end{array}$ & $0,019 \pm 0,003$ & $0,021 \pm 0,007$ & $0,153 \pm 0,021$ \\
Variação do CC & 12,55 a 35,08 & 22,97 a 34,19 & 24,10 a 37,06 \\
$\begin{array}{l}\text { Média do CC } \\
\pm \text { erro padrão }\end{array}$ & $25,73 \pm 1,43$ & $28,38 \pm 1,70$ & $31,05 \pm 0,93$ \\
\hline
\end{tabular}




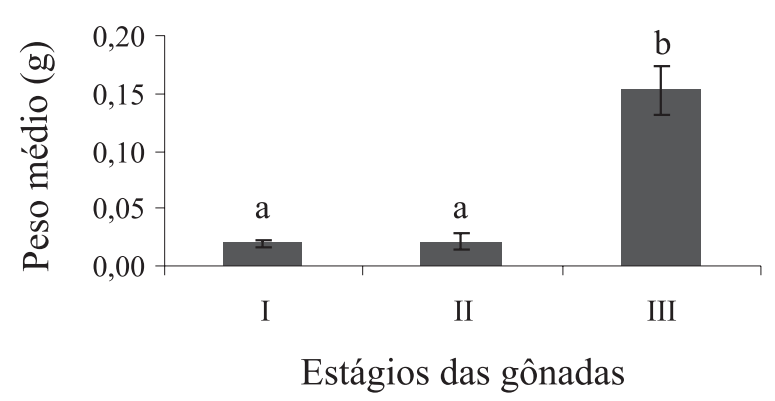

Fig. 1. Peso médio dos ovários de Parastacus varicosus Faxon, 1898 nos três estágios de desenvolvimento. As colunas representam a média e as barras verticais o erro padrão da média. Colunas com pelo menos uma letra em comum não diferem significativamente.

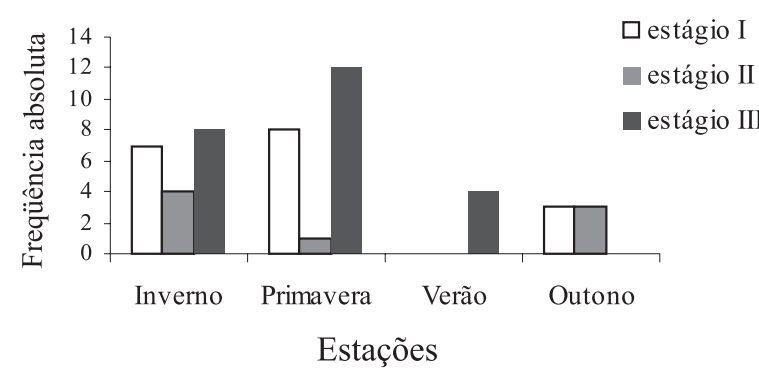

Fig. 2. Frequiência absoluta dos estágios dos ovários de Parastacus varicosus Faxon, 1898 durante o período de junho de 2004 a maio de 2005.

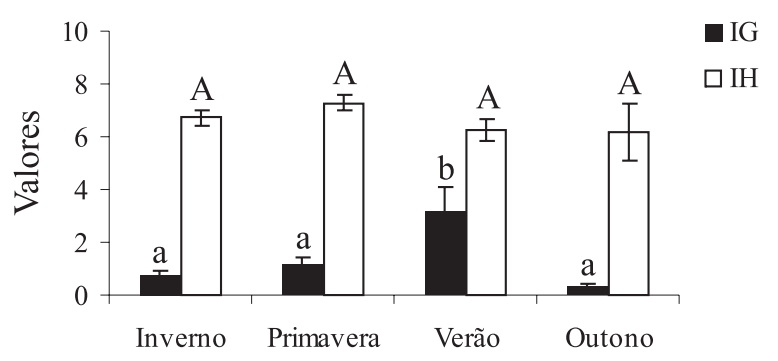

Estações

Fig. 3. Índice gonadossomático (IG) e hepatossomático (IH) sazonal de fêmeas de Parastacus varicosus Faxon, 1898. As colunas representam a média e as barras verticais o erro padrão da média. Colunas com pelo menos uma letra em comum não diferem significativamente; letras minúsculas referentes ao IG e letras maiúsculas referentes ao $\mathrm{IH}$.

Foi observado um aumento significativo do IG no verão (Fig. 3), mostrando que $P$. varicosus apresenta maior atividade reprodutiva nesse período. Entretanto, os valores do IH não apresentaram variação durante o período amostral $(p>0,05)$, no entanto observou-se uma diminuição no período da primavera em relação ao verão (p>0,05).

Comparando-se os IH dos machos e das fêmeas (Fig. 5), verifica-se que não houve variação significativa durante o período amostral $(\mathrm{p}>0,05)$. Para as fêmeas, o

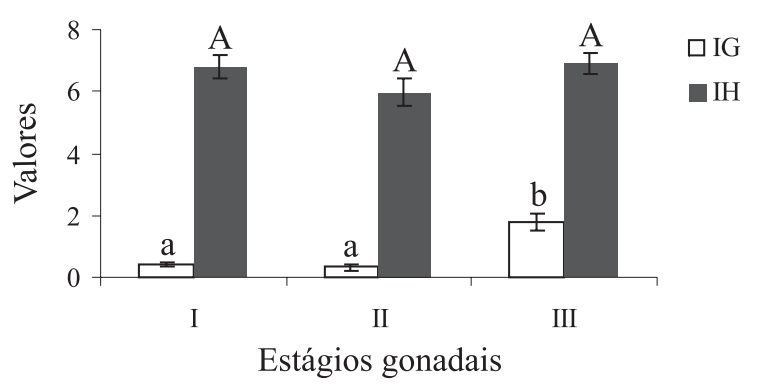

Fig. 4. Índice gonadossomático (IG) e índice hepatossomático (IH) nos estágios de desenvolvimento dos ovários de Parastacus varicosus Faxon, 1898. As colunas representam a média e as barras verticais o erro padrão da média. Colunas com pelo menos uma letra em comum não diferem significativamente; letras minúsculas referentes ao IG e letras maiúsculas referentes ao IH.

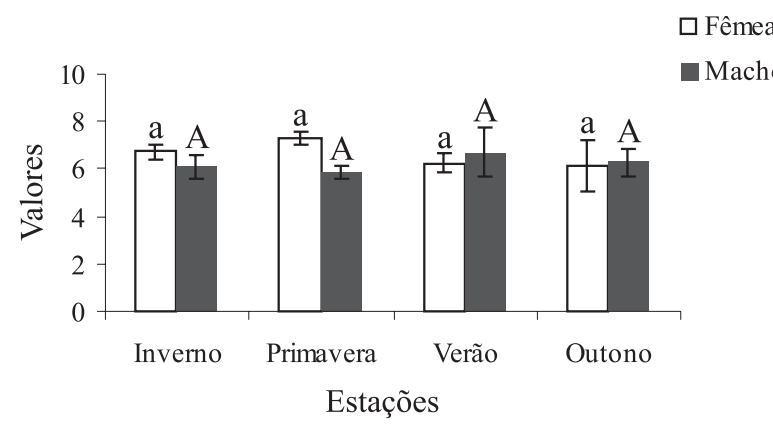

Fig. 5. Índice hepatossomático (IH) dos machos e das fêmeas de Parastacus varicosus Faxon, 1898 nas estações do ano. As colunas representam a média e as barras verticais o erro padrão da média. Colunas com pelo menos uma letra em comum não diferem significativamente; letras minúsculas referentes às fêmeas e letras maiúsculas referentes aos machos.

maior valor do IH ocorreu na primavera $(7,3)$ e o menor, no outono $(6,16)$, enquanto para os machos o maior valor foi observado no verão $(6,71)$ e o menor, na primavera $(5,86)$.

$\mathrm{Na}$ análise histológica dos ovários, foi verificada a presença de oócitos em vitelogênese secundária a partir de $24 \mathrm{~mm}$ (CC), indicando assim que os lagostins estão aptos a se reproduzirem. Em cinco fêmeas menores que $24 \mathrm{~mm}$, constatou-se oócitos em vitelogênese inicial. Nas gônadas masculinas verificou-se espermátides ou espermatozóides em lagostins maiores que $23 \mathrm{~mm}$ (CC).

\section{DISCUSSÃO}

O início da reprodução é um evento crítico na história de vida dos animais e está associado com o esforço reprodutivo, definido como a proporção de energia do corpo transferido para a reprodução (LÓPEZGreco \& Rodriguez, 1999). Nos crustáceos decápodos, em geral, há armazenamento de reservas orgânicas no hepatopâncreas e sua utilização durante o desenvolvimento ovariano foi observado por PILlay \& NAir (1973), Kyomo (1988), Chu (1995), LóPEZ-Greco \& RodRIGUEZ (1999) e YAMAGUCHI (2001); esta característica também foi verificada no lagostim de água doce Cherax quinquecarinatus por LINDQVIST et al. (1999) e BEATTY et al. (2005). 
No entanto, o mesmo não foi observado por RosA \& Nunes (2003) em Aristeus antennatus (Risso, 1816) e Parapenaeus longirostris (Lucas, 1846) (Penaeoidea) e em uma espécie de Nephropoidea, Nephrops norvegicus (Linnaeus, 1758), onde esses autores sugerem que os recursos do hepatopâncreas não são esgotados. $\mathrm{Na}$ presente pesquisa sugere-se apenas uma transferência parcial das reservas do hepatopâncreas de $P$. varicosus para as gônadas durante o período reprodutivo (verão), pois foi observada uma pequena diminuição no peso dessas. Portanto, sugere-se que outros tecidos como a hemolinfa e o músculo e também o aporte de nutrientes oriundos da dieta possam contribuir com a atuação das transferências das reservas durante o período de maturação gonadal (PILlAY \& NAIR, 1973; SPAARGAREN \& HAEFNER, 1994; CAVAlli et al., 2001; Rosa \& NunEs, 2002).

$\mathrm{O}$ aumento do índice gonadossomático no verão pode estar relacionado à amostragem somente de fêmeas com gônadas desenvolvidas. Esse fato deve-se à dificuldade de amostragem nesse período, influenciada pela baixa precipitação. A média histórica da precipitação esperada para os meses do verão (dezembro a fevereiro) para a região seria de 99,63 mm; entretanto, nesse trimestre foi de apenas 25,83 mm (EMBRAPA, 2005). Com o déficit de chuvas, os lagostins aprofundaram as tocas na procura de água, o que dificultou a captura dos mesmos.

Pesquisas realizadas com lagostins do gênero Procambarus por Huner (1988) e GutiéRREZ-YurRuta \& Montes (1999) mostraram que a redução na atividade locomotora das fêmeas ovígeras, associada à diminuição na taxa metabólica, pode explicar a menor amostragem quando comparado com as fêmeas não-ovígeras, as quais apresentam altas taxas metabólicas e maior atividade de forrageio. Segundo BEATTy et al. (2005), essas observações aliadas ao elevado número de tocas ocupadas por fêmeas ovígeras do lagostim Cherax quinquecarinatus sugerem uma possível explicação para a redução na captura das fêmeas ovígeras. Na presente investigação, o fato de não ter sido registrada nenhuma fêmea ovígera durante o período amostral, corrobora com essas observações.

O período reprodutivo em algumas espécies de decápodos é restrito a determinadas épocas do ano, como observado em Chasmagnathus granulatus, Cancer magister (Dana, 1852), Uca lactea (de Haan, 1835) e Aegla leptodactyla Buckup \& Rossi, 1977 por LóPEZ-GRECO \& RodríGuEZ (1999), SwinEY \& SHIRLEY (2001), YAMAGUCHI (2001) e Noro \& BucKup (2003), respectivamente. No entanto, fêmeas ovígeras de A. platensis foram registradas durante todo ano, mostrando assim que esta espécie tem a capacidade de reproduzir-se por um período mais prolongado (BUENO \& BOND-BUCKUP, 2000).

Com relação aos lagostins de água doce, FonTourA \& Buckup (1989) verificaram que o período reprodutivo de Parastacus brasiliensis (von Martens, 1869) inicia nos meses da primavera e estende-se até os meses do verão. Este mesmo período foi observado em $P$. varicosus na presente pesquisa.

A utilização de parte das reservas de nutrientes do hepatopâncreas por $P$. varicosus durante o período reprodutivo, indica uma estratégia pouco comum entre os crustáceos. Tal fato pode ser atribuído ao hábito de vida desse lagostim, que vive em ambiente com recursos alimentares limitados, confinados em galerias, e em pequenas populações. Outras investigações sobre a dinâmica populacional das espécies de Parastacus deverão ser implementadas visando um melhor entendimento das estratégias reprodutivas dos lagostins de água doce.

\section{REFERÊNCIAS BIBLIOGRÁFICAS}

Baptista-Metri, C.; Pinheiro, M. A. A.; Blankensteyn, A. \& Borzone, C. A. 2005. Biologia populacional e reprodutiva de Callinectes danae Smith (Crustacea, Portunidae), no Balneário Shangrilá, Pontal do Paraná, Paraná, Brasil. Revista Brasileira de Zoologia 17(1):43-49.

Beatty, S. J.; Morgan, D. L. \& Gill, H. S. 2005. Life history and reproductive biology of the gligie, Cherax quinquecarinatus, a freswater crayfish endemic to southwestern Australia. Journal of Crustacean Biology 25(2):251-262.

Bueno, A. A. P. \& Bond-Buckup, G. 2000. Dinâmica populacional de Aegla platensis Schmitt (Crustacea, Decapoda, Aeglidae). Revista Brasileira de Zoologia 17(1):43-49.

Castiglioni, D. S. \& Santos, S. 2001. Reproductive aspects of Cyrtograpsus angulatus Dana, 1851 (Brachyura, Grapsidae) in the Lagoa do Peixe, Rio Grande do Sul State, Brazil. Nauplius 9(1):11-20.

Cavalli, R. O.; Tamtin, M.; Lavens, P. \& Sorgeloos, P. 2001. Variations in lipids classes and fatty acid content in tissues of wild Macrobrachium rosenbergii (de Man) females during maturation. Aquaculture 193:311-324.

CHu, K. H. 1995. Aspects of reproductive biology of the shrimp Metapenaeus joyneri from the Zhujiang Estuary, China. Journal of Crustacean Biology 15(2):214-219.

Cobo, V. J. \&. Fransozo, A. 2005. Physiological maturity and relationships of growth and reproductive in the red mangrove crab Goniopsis cruentata (Latreille) (Brachyura, Grapsidae) on the coast of São Paulo, Brazil. Revista Brasileira de Zoologia 22(1):219-223.

EMBRAPA (Empresa Brasileira de Pesquisa Agropecuária). 2005. Sistema de Monitoramento Agrometeorológico. Disponível em: <www.agritempo.com.br>. Acesso em: 10.11.2005.

Fontoura, N. F. \& Buckup, L. 1989. Dinâmica populacional e reprodução em Parastacus brasiliensis (von Martens, 1869) (Crustacea, Decapoda, Parastacidae). Revista Brasileira de Biologia 49(4):911-921.

Gibson, R. \& BARKer, P. L. 1979. The decapod hapatopancreas. Oceanography Marine Biology: an annual review 17:285-346.

Grant, A. \& Tyler, P. A. 1983. The analysis of data in studies of invertebrate reproduction. I. Introduction and statistical analysis of gonad indices and maturity indices. International Journal of Invertebrate Reproduction 6:259-269.

Grassé, P. P. 1996. Traité de Zoologie: Anotomie, Systématique, Biologie. Tome VII. Crustacés; fascicule I: Morphologie, Physiologie, Reproduction, Systématique. Paris, Masson. $917 \mathrm{p}$.

Gutiérrez-Yurruta, P. J. \& Montes, C. 1999. Bioenergetics and phenology of reproduction of the introduced red swamp crayfish, Procambarus clarkii, in Donana National Park, Spain, and implications for species management. Freshwater Biology 42:561-574.

Haefner, P. A. \& SpaArgaren, D. H. 1993. Interactions of ovary and hepatopancreas during the reproductive cycle of Crangon crangon (L.). I. Weight and volume relationships. Journal of Crustacean Biology 13(3):523-531

Huner, J. V. 1988. Procambarus in North America and elsewhere. In: Holdich, D. M. \& Lowery, R. S. eds. Freshwater Crayfish: biology, management and exploitation. London, Chapman and Hall. p.239-261.

Krol, R. M.; Hawkins, W. E. \& Overstreet, R. M. 1992. Reproductive components. In: Harrison, F.W. \& Humes, A, G. eds. Microscopic Anatomy of Invertebrates. New York, Willey-Liss. v.10, p.295-343.

Kulkarni, G. K.; Glade, L. \& Fingerman, M. 1991. Oogenesis and 
effects of neuroendocrine tissues on in vitro synthesis of protein by the ovary of the red swamp crayfish Procambarus clarkii (Girard). Journal of Crustacean Biology 11(4):513-522.

Күомо, J. 1988. Analysis of the relationship between gonads and hepatopancreas in males and females of the crab Sesarma intermedia, with reference to resource use and reproduction. Marine Biology 97:87-93.

Lawrence, J. M. 1976. Patterns of lipid storage in postmetamorphic marine invertebrates. American Zoologist 16:747-762.

Lindevist, O. V.; Huner, J. V.; Henttonen, P. \& Kononen, H. 1999. A comparison of life history strategies and energy reserves of crayfishes occupying permanent an temporary water bodies. Freshwater Biology 12:449-461.

López-Greco, L. S. \& Rodríguez, E. M. 1999. Annual reproduction and growth os adult crabs Chasmagnathus granulata (Crustacea, Brachyura, Grapsidae). Cahiers De Biologie Marine 40:155-164.

Mantelatto, F. L. M. \& Fransozo, A. 1997. Fecundity of the crab Callinectes ornatus Ordway, 1863 (Decapoda, Brachyura, Portunidae) from the Ubatuba Region, São Paulo, Brazil. Crustaceana 70(2):214-225.

Noro, C. K. \& Buckup, L. 2003. O crescimento de Aegla leptodactyla Buckup \& Rossi (Crustacea, Anomura, Aeglidae). Revista Brasileira de Zoologia 20(2):191-198.

Оh, C. W.; Suh, H. L.; PArk, K. Y.; MA, C. W. \& Lim, H. S. 2002. Growth and reproductive biology of the freshwater shrimp Exopalaemon modestus (Decapoda: Palaemonidae) in a lake of Korea. Journal of Crustacean Biology 22(2):357-366.

Pillay, K. K. \& NaIR, N. B. 1973. Observations on the biochemical changes in gonads and other orgasn of Uca annulipes, Portunus pelagicus and Metapenaeus affinis (Decapoda: Crustacea) during the reproductive cycle. Marine Biology 18:167-198.
Reigada, A. L. D. \& Negreiros-Fransozo, M. L. 1999. Maturidade sexual em Hepatus pudibundus (Decapoda, Brachyura, Portunidae), in Ubatuba littoral, São Paulo State, Brazil. Crustaceana 71(4):434-452.

Rosa, R. A. \& Nunes, M. L. 2002. Biochemical changes during the reproductive cycle of the deep-sea decapod Nephrops norvegicus on the south coast of Portugal. Marine Biology 141: $1001-1009$.

. 2003. Changes in organ indices and lipid dynamics during the reproductive cycle of Aristeus antennatus, Parapenaeus longirostris and Nephrops norvegicus (Crustacea: Decapoda) females from the south Portuguese coast. Crustaceana 75(9): 1095-1105.

Sagi, A.; Khalaila I.; Barki, A.; Hulata, G. \& Karplus, I. 1996. Intersex red claw crayfish Cherax quadricarinatus (von Martens): functional males with previtellogenic ovaries. Biology Bulletin 190:16-23.

SpaArgaren, D. H. \& HaEFner, O. A., JR. 1994. Interactions of ovary and hepatopancreas during the reproductive cycle of Crangon crangon (L.). II. Biochemical relationships. Journal of Crustacean Biology 14:6-19.

SWiney, K. M. \& Shirley, T. 2001. Gonad development of southeastern Alaskan Dungeness crab, Cancer magister, under laboratory conditions. Journal of Crustacean Biology 21(4):897-904.

Vazzoler, A. E. A. De M. 1996. Biologia da Reprodução de Peixes Teleósteos: Teoria e Prática. São Paulo, CNPq/ Nupelia (UEM). 169p.

Yamaguchi, T. 2001. Seasonal change of the hepatopâncreas index in the males of the fiddler crab, Uca lactea. Crustaceana 4(7):627-634.

ZAR, J. H. 1996. Biostatistical analysis. Prentice-Hall, Upper Saddle Rover. 662p.

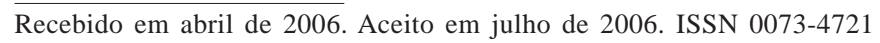
Artigo disponível em: www.scielo.br/isz 